\title{
Rancang Bangun Alat Deteksi Kecelakaan Sepeda Motor Berbasis Exponential Smoothing
}

\author{
Titania Nur Alifah ${ }^{1}$ Harianto $^{2}$ Ira Puspasari $^{3}$ \\ Program Studi Teknik Komputer Universitas Dinamika \\ Email: ${ }^{1}$ titanianuralifah@gamil.com, ${ }^{2}$ hari@dinamika.ac.id, ${ }^{3}$ ira@dinamika.ac.id
}

\begin{abstract}
Abstrak: Keterlambatan pada korban kecelakaan karena lokasi kecelakaan yang sepi mengakibatkan korban kecelakaan bisa meninggal ditempat. Maka dari itu, diciptakannya alat ini untuk mendeteksi kecelakaan pada sepeda motor. Alat ini menggunakan tiga sensor yaitu sensor SW420 sebagai deteksi getaran, sensor GY521 MPU6050 sebagai deteksi kemiringan dan Modul GPS untuk mendeteksi lokasi. Ketika sepeda motor mengalami kecelakaan, maka akan ada pesan ke aplikasi telegram berupa notifikasi kecelakaan dan lokasi kecelakaan ke aplikasi telegram. Hasil dari pengujian yang telah dilakukan dapat disimpulkan bahwa alat tersebut sudah berhasil di uji coba jatuh dengan rata-rata delay pengiriman ke aplikasi telegram 4.5 detik. Selain itu, modul GPS sudah berhasil mendeteksi lokasi secara tepat dengan error pada latitude sebesar $0.00072749 \%$ dan error pada longitude sebesar $0.00003389 \%$. Pada penelitian ini penulis mendapatkan hasil uji yang telah membuktikan bahwa penggunaan metode exponential smoothing dapat mengurangi error pada sensor MPU6050. ketika telah dilakukan uji coba error yang dihasilkan oleh MPU6050 dengan menggunakan metode exponential smoothing bernilai $7.835 \%$ saat sensor miring kanan dan $12.133 \%$ saat sensor miring kiri. Sedangkan, error dari sensor MPU6050 tanpa menggunakan metode exponential smoothing adalah $9.214 \%$ saat sensor miring kanan dan $16.197 \%$ saat sensor miring kiri.
\end{abstract}

Kata Kunci : Deteksi Kecelakaan, Exponential Smoothing, Telegram Bot, IoT, Android.

\begin{abstract}
Delay in accident victims due to the quiet location of the accident resulting in accident victims can die on the spot. Therefore, the creation of this tool to detect accidents on motorbikes. This tool uses three sensors namely SW420 sensor as vibration detection, GY521 MPU6050 sensor as tilt detection and GPS Module to detect location. When a motorcycle has an accident, there will be a message to the telegram application in the form of an accident notification and accident location to the telegram application. The results of the tests that have been carried out can be concluded that the device has been successfully tested in the fall with an average delay of sending to the telegram application 4.5 seconds. In addition, the GPS module has successfully detected the exact location with an error at latitude of $0.00072749 \%$ and error at longitude of $0.00003389 \%$. In this study the authors get test results that have proven that the use of exponential smoothing methods can reduce errors on the MPU6050 sensor. when testing the error generated by the MPU6050 using the exponential smoothing method was worth $7,835 \%$ when the sensor tilted right and $12,133 \%$ when the sensor tilted left. Meanwhile, the error of the MPU6050 sensor without using the exponential smoothing method was $9.214 \%$ when the sensor tilted right and $16.197 \%$ when the sensor tilted left. Keywords: Accident Detection, Exponential Smoothing, Telegram Bot, IoT, Android.
\end{abstract}

\section{PENDAHULUAN}

Semakin majunya perkembangan ilmu pengetahuan dan teknologi (IPTEK) saat ini, semakin banyak sarana dan prasarana yang diciptakan khususnya bidang transportasi. Transportasi pada era modern ini merupakan kebutuhan primer untuk semua orang. Seiring dengan perkembangan zaman jumlah alat transportasi yang semakin banyak berbanding lurus dengan tingkat kejadian kecelakaan lalu lintas.

Kecelakaan dapat mengakibatkan kerugian berupa material akibat kerusakaan ataupun penderitaan korban kecelakaan tersebut, bahkan kecelakaan dapat mengakibatkan kematian, Kecelakaan bisa disebabkan karena 
Tania Nur Alifah, dkk//Journal of Technology and Informatics (JoTI) Vol.1, No.2, April 2020, 108119

mengantuk, bermain handphone, berbicara saat berkendara yang dapat mengganggu konsentrasi. Tidak hanya merugikan diri sendiri, kecelakaan juga dapat merugikan orang lain yang bahkan tidak melakukan kesalahan sama sekali. Kecelakan lalu lintas sering didominasi oleh kendaraan roda dua karena sering melakukan pelanggaran lalu lintas dengan kebut-kebutan dan kurangnya perlengkapan pada sepeda motor. Keterlambatan dalam penanganan korban kecelakaan sering terjadi dikarenakan terlambatnya informasi yang diterima oleh pihak kepolisian maupun rumah sakit terdekat. Saat ini kepolisian maupun rumah sakit hanya bergantung pada informasi masyarakat. Hal ini memiliki kekurangan karena pihak kepolisian maupun rumah sakit melakukan tindakan saat ada masyarakat yang melapor. Saat terjadi kecelakaan ada kalanya jika tempat kecelakaan tersebut jauh dari kantor polisi dan rumah sakit terdekat sehingga masyarakat yang melapor juga terlambat untuk memberi informasi. Sehingga korban meninggal di tempat sering terjadi karena kurangnya penanganan yang saat itu juga dibutuhkan.

Pada penelitian alat deteksi kecelakaan yang sudah ada, hanya menggunakan satu sensor yaitu sensor Accelerometer dan untuk pengiriman pesan notifikasi ketika mengalami kecelakaan menggunakan SMS Gateway. Namun sistem ini memiliki kelemahan yaitu hanya mengukur kemiringan pada saat kecelakaan saja dan juga komunikasi yang digunakan menggunakan SMS dan juga alat tersebut masih diterapkan pada mobil [1]. Selain itu pada penelitian yang berjudul sistem pendeteksi kecelakaan pada sepeda motor berdasarkan kemiringan menggunakan sensor Gyroscope berbasis arduino masih menggunkan satu sensor yang hanya mendeteksi kemiringan saja dan juga sistem komunikasi untuk pengiriman lokasi kecelakaan masih menggunakan SMS [2].

Pada Tugas Akhir ini alat tersebut dikembangkan dengan menggunakan dua sensor sebagai pendeteksi kecelakaan dan mengirimkan pesan berupa notifikasi dan lokasi bahwa telah terjadi kecelakan pada sepeda motor dengan menggunakan aplikasi telegram ke pemilik motor dan keluarga secara broadcast. Untuk memberikan informasi kecelakaan diperlukan sistem yang mendukung deteksi kecelakaan yaitu dengan menggunakan sensor Accelerometer dan Gyroscope (MPU6050) untuk mengukur kemiringan dan derajat ketika motor tersebut jatuh. Sensor MPU6050 tersebut diolah menggunakan metode Exponential Smoothing untuk menghasilkan data yang menggunakan metode Exponential Smoothing untuk menghasilkan data yang akurat dan rendah dari noise. Sensor MPU6050 merupakan salah satu sensor yang tergolong dalam Inertial Measurement Unit (IMU), sensor ini merupakan gabungan dari 3-axis gyroscope dan 3-axis accelerometer. Pada penggunaannya, sensor ini dapat memberikan keluaran sudut kemiringan pada sumbu $\mathrm{X}$ dan $\mathrm{Y}$ yang dapat digunakan untuk mendeteksi derajat kemiringan pada saat sepeda motor jatuh. Pada saat sepeda motor terjatuh dan alat mendeteksi keluaran berupa derajat kemiringan pada sensor Mpu6050, data keluaran sensor ini memiliki banyak noise yang sangat mengganggu pembacaan dari sensor. Oleh karena itu digunakanlah Exponential Smoothing ini untuk mengolah data dari sensor yang memiliki banyak noise agar dapat mengestimasikan data sebenarnya dari sensor tersebut. Exponential Smoothing adalah suatu metode peramalan ratarata bergerak yang melakukan pembobotan menurun secara exponential terhadap nilai-nilai observasi yang lebih tua [3]. Untuk memperbaiki sinyal dan mendapatkan nilai output yang halus dan stabil, maka perlu ditambahkan metode Exponential Smoothing untuk merapikan data dari statistik mikrokontroler Node MCU dan sensor Mpu6050. Penggunaan metode tersebut bertujuan untuk mendapatkan nilai derajat yang lebih halus dan tidak memiliki banyak noise agar dalam memproses data dari sensor Mpu6050 menjadi lebih akurat.

Pada penelitian sebelumnya banyak membahas tentang Exponential Smoothing untuk meredam noise atau mengurangi noise pada sensor seperti perancangan robot berkaki 4 (Quadruped) dengan stabilization algorithm pada uneven floor menggunakan 6-dof imu berbasis invers kinematic [4]. Dimana pada penelitian tersebut menggunakan metode exponential smoothing untuk membuat suatu deretan data yang berurutan waktu menjadi lebih halus [4]. Selain itu, pada penelitian visualisasi dan monitoring lokasi kebakaran pada security room, metode exponential smoothing digunakan untuk mengambil rata-rata dan menghilangkan pengaruh data iregular yang bersifat random. Exponential Smoothing ini merupakan perkembangan dari metode Moving Average [3]. 
Selain digunakan untuk memperhalus data keluaran dari sensor, metode Exponential Smoothing ini juga digunakan untuk meramal nilai di masa mendatang, seperti pada penelitian Sistem peramalan stok obat menggunakan metode exponential smoothing [5].

Selain menggunakan sensor MPU6050 pada tugas akhir menggunakan sensor getaran (SW-420) untuk mendeteksi getaran atau benturan ketika sepeda motor mengalami kecelakaan. alat tersebut mendeteksi kemiringan ketika motor terjatuh dan mendeteksi getaran yang dialami sepeda motor ketika mengalami kecelakaan maka dapat mempermudah untuk mendeteksi sepeda motor tersebut mengalami kecelakaan atau tidak dan dapat mengirimkan notifikasi ketika sepeda motor mengalami kecelakaan melalui aplikasi telegram.

\section{METODE PENELITIAN}

Pada metode penilitian dibawah ini terdapat input dan output pada alat pendeteksi kecelakaan.

1. Input Pada ESP8266

a. Sensor GY521 MPU6050 : digunakan untuk mendeteksi kemiringan

b. Sensor Getaran SW420 : digunakan untuk mendeteksi getaran

c. Modul GPS : digunakan untuk mendeteksi lokasi

2. Output pada ESP8266

a. Telegram : digunakan untuk komunikasi dan pengiriman notifikasi kecelakaan.

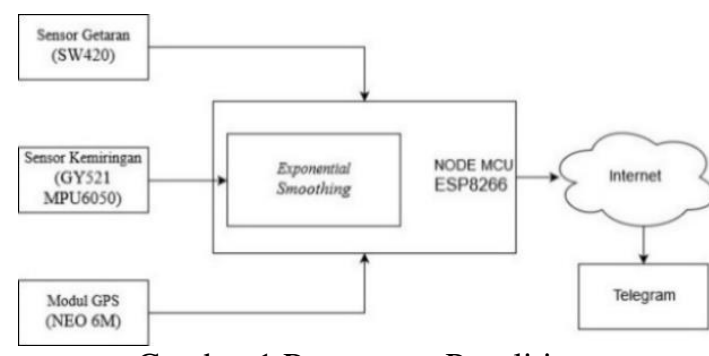

Gambar 1 Rancangan Penelitian

Pada Gambar 1 di atas terdapat skema blok diagram dimana terdapat pusat kontrol yaitu ESP8266 untuk mengkoneksikan ke internet karena pada alat ini menggunakan komunikasi wireless. Alat ini memilki input berupa sensor MPU6050, sensor Getaran (SW420), Modul GPS. Untuk output terdapat Aplikasi Telegram pada handphone untuk mengirimkan pesan notifikasi bahwa telah terjadi kecelakaan sekligus lokasi kecelakaan tersebut terjadi. Cara kerja sistem ini yaitu dengan mendeteksi adanya getaran yang diambil dari data sensor Getaran SW420, indikator getaran untuk kecelakaan adalah diatas 700 ADC. Sensor MPU6050 menggunakan Exponential Smoothing dengan perhitungan kontrol yang berutujuan untuk mengurangi noise pada sensor MPU6050. Perhitungan metode tersebut diolah di dalam Node Mcu. Exponential Smoothing diimplementasikan untuk proses penyaringan noise data pada output dari MPU6050 sebelum data tersebut diolah pada mikrokontroller. Perancangan menggunakan Exponential Smoothing dilakukan dengan menggabungkan data pembacaan dari accelerometer dan gyroscope yang kemudian diolah untuk menghasilkan sudut kemiringan yang sebenarnya pada sumbu $\mathrm{X}$ dan $\mathrm{Y}$, sehingga sudut keluaran dari sensor tersebut tidak memiliki banyak noise.

\section{Perancangan Software}

Pada alat ini, set point untuk mendeteksi getaran yang diakibatkan kecelakaan pada sepeda motor adalah nilai adc lebih dari 700. Untuk membedakan getaran akibat kecelakaan atau getaran dari sepeda motor itu sendiri maka diperlukan kalibrasi sensor yang detail dan dilakukan uji coba beberapa kali. Sedangkan pada sensor MPU6050 atau sensor Accelerometer \& Gyroscope yaitu sensor yang mendeteksi kemiringan dan derajat ketika motor terjatuh, pada alat ini set point yang diberikan pada sensor MPU6050 adalah untuk kemiringan saat motor terjatuh pada sebelah kiri yaitu anatar 40 derajat sampai dengan 80 derajat, sedangkan untuk kemiringan saat motor terjatuh pada sebelah kanan yaitu antara -40 denagan 80 derajat.. ketika motor terjatuh lebih dari set point yang telah ditentukan, maka bisa dipastikan bahwa motor tersebut mengalami kecelakaan dengan melihat getaran yang dihasilkan oleh sepeda motor tersebut ketika mengalami kecelakaan. Pada sensor Mpu6050 diolah dengan menggunakan perhitungan Exponential Smoothing. Data Accelerometer dikonversi terlebih dahulu, kemudian difilter menggunakan Exponential Smoothing Filter. Data yang difilter tersebut adalah nilai roll dari accelerometer. Flowchart sistem terlihat seperti gambar 2 dibawah ini. 


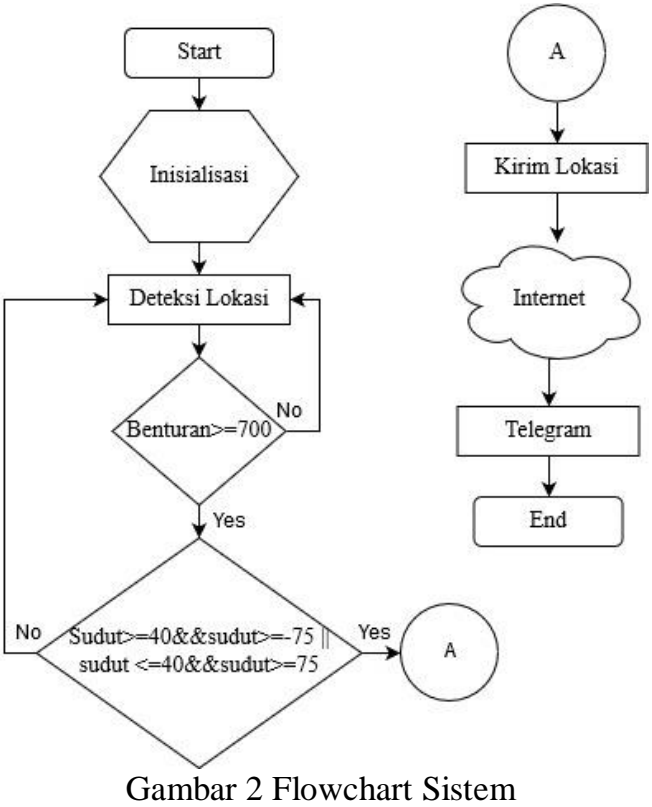

Untuk ilustrasi dari Sensor MPU6050

Berikut terlihat pada gambar 3 dibawah ini

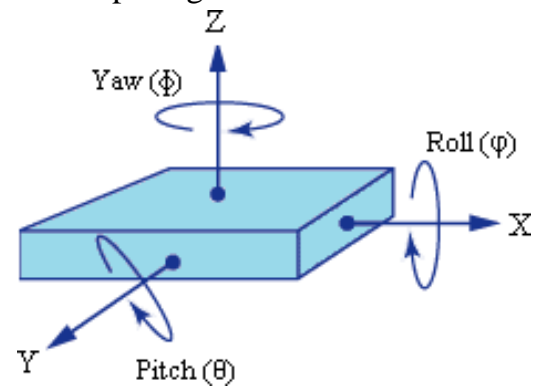

Gambar 3 Ilustrasi MPU6050

Gambar 3 di atas merupakan ilustrasi dari sutu pitch, roll dan yaw pada sensor MPU6050. Pada alat ini, sudut yang digunakan yaitu sudu roll, yaitu sudut rotasi yang mengelilingi sumbu X. Nilai Accelerometer yang terkena derau tersebut difilter menggunakan metode Exponential Smoothing. Nilai accelerometer yang telah difilter menggunakan metode tersebut dikonversi ke dalam bentuk sudut pitch atau roll. Nilai sudut pitch dan roll dapat menggunakan persamaan berikut,

$\theta=\tan ^{-1}\left(a_{y} / \sqrt{ } a^{2} \mathrm{x}+a^{2} \mathrm{z}\right)$

$\varphi=\tan ^{-1}\left(a_{x} / \sqrt{ } a^{2} y+a^{2} z\right)$,

dimana $a_{x}$ merupakan nilai accelerometer pada sumbu-X, $a_{y}$ merupakan nilai accelerometer pada sumbu-Y, dan $a_{z}$ merupakan nilai accelerometer sumbu-Z [6].

\section{Perancangan Hardware}

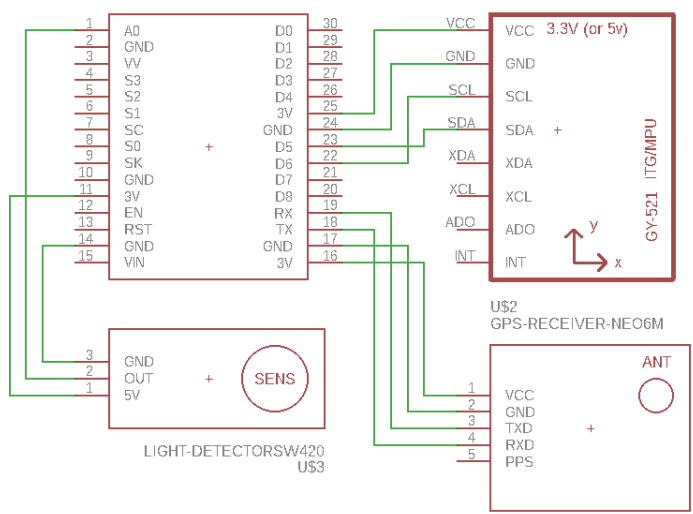

Gambar 4 Perancangan Hardware

Pada rangkaian alat Gambar 4 di atas terdapat sensor getaran SW420 yang mana sensor tersebut akan mendeteksi getaran saat sepeda motor mengalami kecelakaan. Sensor SW420 disambungkan pada data analog dari Node Mcu sedangkan untuk sensor MPU6050 adalah sensor yang akan membaca dan mendeteksi kemiringan pada sepeda motor saat mengalami kecelakaan. Jalur data yang digunakan pada sensor MPU6050 adalah jalur data SDA dan SCL yang disambungkan dengan pin SDA dan SCL Node Mcu dan yang terakhir untuk modul GPS jalur data yang digunakan untuk menghubungkan pada Node Mcu adalah Rx dan Tx dari modul GPS yang disambungkan pada pada $\mathrm{Rx}$ dan Tx pada Node Mcu. Power yang digunakan untuk menghidupkan alat tersebut adalah daya dari power bank.

\section{Perancangan GY521 MPU6050}

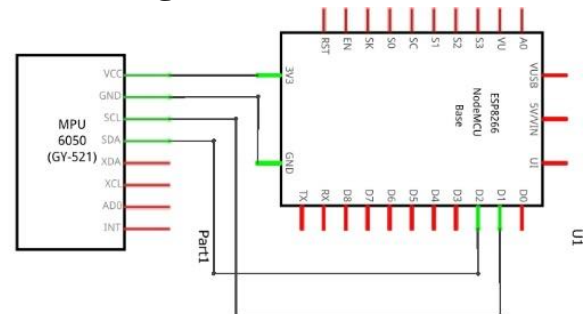

Gambar 5 Perancangan MPU6050

Pada gambar 5 di atas dijelaskan bahwa fungsi pada sensor GY521 MPU6050 adalah untuk mendeteksi kemiringan suatu benda dengan mengambil nilai yaw, pitch dan roll pada sensor tersebut. Nilai yaw, pitch dan roll yang diambil pada tugas akhir ini adalah nilai dari pitch accelerometer. 


\section{Perancangan Exponential Smoothing}

Output pada Sensor MPu6050 pada program Arduino IDE pada sudut pitch (y) difilter terlebih dahulu menggunakan Exponential Smoothing agar tidak ada derau atau noise. Sehingga keluaran dari sensor tersebut lebih halus. Berikut persamaan dari Exponential Smoothing

$S t=\alpha \cdot Y t+(1-\alpha) \cdot S t-1$

Dimana :

$S_{t} \quad$ : adalah output dari filter pada saat bersamaan dengan $\mathrm{t}$

$Y_{t} \quad$ : adalah input baru pada saat bersamaan dengan $\mathrm{t}$

$S t-1 \quad$ : adalah output filter sebelumnya

$S_{1} \quad$ : adalah nilai output data saat ini

$Y_{1} \quad$ : adalah nilai input data baru

Keakuratan hasil ramalan (forecasting) dengan metode single exponential smoothing sangat tergantung pada konstanta pemulusan yang digunakan [7]. Hanya ada satu parameter konstanta pemulusan $\alpha$ yang harus dievaluasi dalam metode pemulusan eksponensial tunggal. Pendekatan untuk memilih nilai $\alpha$ yang optimal biasanya dilakukan secara coba-coba (trial and error). Sementara itu, nilai konstanta pemulusan $\alpha$ tergantung pada kriteria perhitungan error yang digunakan. Akibatnya, nilai-nilai ramalan akan sangat bervariasi, tergantung pada nilai-nilai $\alpha$ yang digunakan [8].

Pada tugas akhir ini, nilai $\alpha$ yang digunakan adalah 0,2, karena menurut [9]. menyarankan agar menggunakan konstanta pemulusan $\alpha<0,5$ dan nilai 0,2 dan 0,3 dinyatakan memberi nilai yang baik.

\section{Perancangan SW420}

Pada Gambar 6 di bawah ini adalah perancangan Sensor SW420 yaitu sensor Vibration untuk mendeteksi suatu getaran benda. Pada tugas akhir ini, Sensor SW420 digunakan untuk mengukur getaran yang dihasilkan saat sepeda motor mengalami kecelakaan. Sensor SW420 memiliki keluaran Output Digital yaitu 0 (LOW) dan 1 (HIGH). Tetapi pada tugas akhir ini, Output yang dikeluarkan dari sensor SW420 ini adalah nilai ADC dimana nilai minimum adalah 1 dan nilai maksimum adalah 1024 .

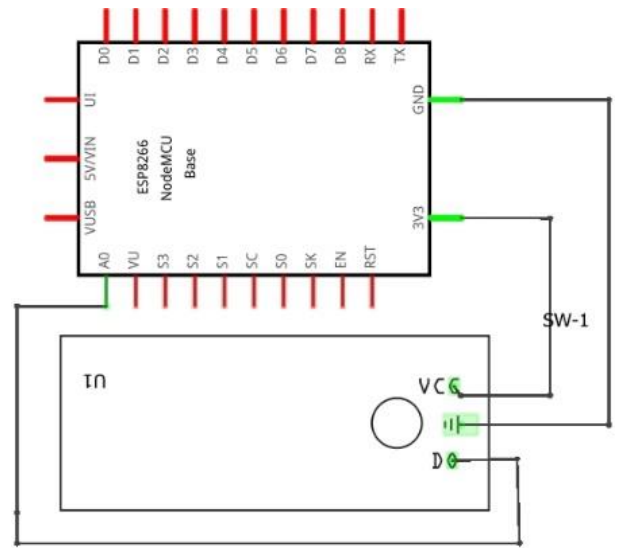

Gambar 6 Perancangan SW420

\section{Perancangan Modul GPS}

Pada Gambar 7 di bawah ini, perancangan GPS digunakan untuk mendeteksi lokasi suatu tempat atau koordinat dimana modul GPS itu berada. Modul GPS yang digunakan adalah U-blok NEO-6M GPS yang dapat mendeteksi titik garis lintas (Latitude) dan garis bujur (Longitude). Modul Neo-6M GPS berkomunikasi dengan Arduino melalui komunikasi serial menggunakan pin TX dan RX. TX adalah Transmitter yang berfungsi mengirim data/mengeluarkan data atau merupakan jalan yang dilalui dalam mengirim data antar device. Data akan dikirim melalui Tx (Transmitter) dan diujung lainnya data akan diterima melalui $\mathrm{Rx}$ (Received). Sedangkan $\mathrm{Rx}$ adalah jalur penerimaan data dari suati device ke device lain. $\mathrm{Rx}$ biasa disebut Received yang berfungsi sebagai menangkap data yang dikirim oleh Tx (Transmitter).

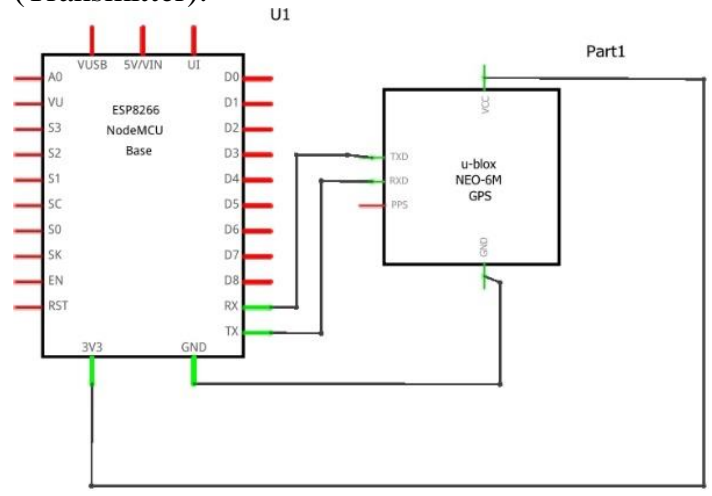

Gambar 7 Perancangan Modul GPS 


\section{Perancangan Telegram Bot}

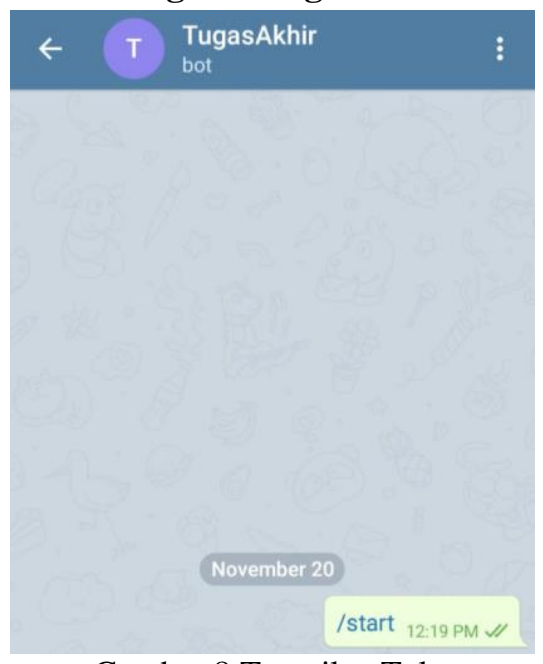

Gambar 8 Tampilan Telegram

Pada Gambar 8 diatas adalah hasil dari Aplikasi telegram bot yang telah dibuat. Aplikasi Telegram adalah sebuah Aplikasi yang digunakan untuk mengirimkan Lokasi Kecelakaan pada penelitian ini.

\section{Desain Hardware}

Desain dari sistem pendeteksi kecelakaan akan ditempatkan pada jok sepeda motor dan dikemas menggunakan Blackbox. Pada alat tersebut juga dipasang powerbank sebagai power agar alat tersebut dapat menyala. Berikut adalah desain hardware yang dapat dilihat pada gambar 9 dibawah ini.

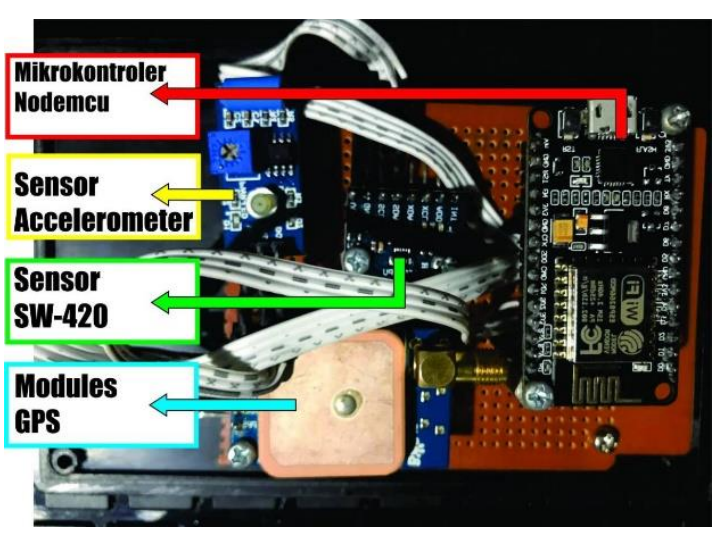

Gambar 9 Desain Hardware

\section{HASIL DAN PEMBAHASAN}

Terdapat beberapa tahap yag dilakukan dalam pengujian pada penelitian ini yaitu, meliputi pengujian terhadap perangkat keras (hardware) dan juga pengujian terhadap perangkat lunak (software). Pengujian perangkat keras sendiri terdiri dari pengujian keakuratan dari sensor GY521 Mpu6050 menggunakan metode Exponential Smoothing, keakuratan sdari sensor getaran SW420, keakuratan lokasi yang diterima oleh modul GPS Neo 6M dan pengiriman dari esp8266 ke telegram apakah dapat dikirim secara real time. Diharapkan hasil yang didapatkan merupakan hasil yang sesuai dengan harapan sehingga penelitian ini dapat diterapkan secara real.

\section{Pengujian Sensor GY521 MPU6050}

Tujuan dari pengujian ini adalah untuk mengetahui tingkat keakuratan sensor GY521 MPU6050 apakah nilai sudut yang dikeluarkan sama dengan aslinya. Sudut yang diambil pada sensor GY521 MPU6050 adalah sudut pitch (y). pada pengujian ini, terdapat pengujian 2 tahap yaitu pengujian sensor saat dimiringkan ke kanan dan pengujian sensor saat dimiringkan ke kiri. Hasil dari pengujian bisa dilihat pada tabel 1 dibawah ini.

Tabel 1 menunjukkan hasil pengujian sensor ketika dimiringkan ke kanan dengan menggunakan busur untuk menentukan perbandingan dan error pada sensor MPU6050 tersebut. Untuk melakukan pengujian saat sensor dimiringkan ke kiri bisa dilihat pada tabel 2 .

Hasil pengujian terhadap sensor MPU6050 terhadap sudut pitch (y) dengan melakukan pergerakan ke kanan dan ke kiri bisa disimpulkan bahwa nilai sudut pitch (y) yang keluar dari serial monitor tidak sama dengan nilai asli pada busur dimana pada saat miring kanan nilai rata-rata error pada sudut $30^{\circ}$ adalah $7.933 \%$ dengan rata-rata selisih sebesar $0.408^{\circ}$ pada sudut 60 rata-rata error nya adalah $8.703 \%$ dengan ratarata selisih sebesar $0.404^{\circ}$ dan pada sudut 90 ratarata error nya adalah $11.006 \%$ dengan rata-rata selisih adalah $0.58^{\circ}$. Sedangkan untuk miring kiri, error pada sudut $30^{\circ}$ adalah $22.34 \%$ dengan rata-rata selisih sebesar $0.164^{\circ}$, pada sudut 60 adalah $14.132 \%$ dengan rata-rata selisih sebesar $0.622^{\circ}$ dan pada sudut 90 rata-rata error nya adalah $11.163 \%$ dengan rata-rata selisih sebesar $0.422^{\circ}$. Hasil dari pengujian tersebut dapat 
Tania Nur Alifah, dkk//Journal of Technology and Informatics (JoTI) Vol.1, No.2, April 2020, 108119

disimpulkan bahwa nilai sudut y yang keluar pada sensor tersebut terlihat kurang akurat dan perubahannya tidak stabil dikarenakan pada sensor MPU6050 terdapat noise.

Tabel 1 Pengujian Sensor Miring Kanan

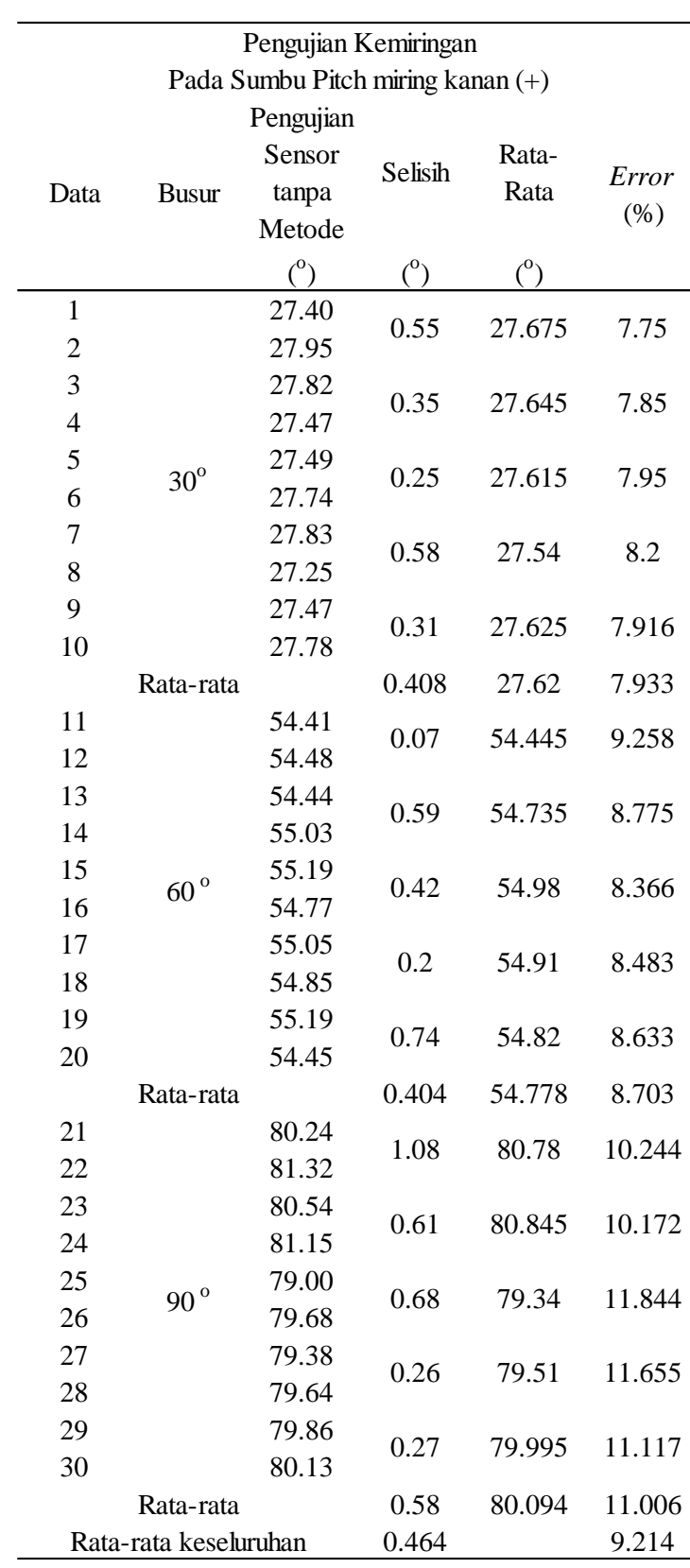

Tabel 2 Pengujian Sensor Miring Kiri

Pengujian Kemiringan
Pada Sumbu Pitch miring kiri (-)
Pengujian
Data Busur $\begin{gathered}\text { Sensor } \\ \text { tanpa } \\ \text { Metode }\end{gathered}$ Selisih Rata-rata Error

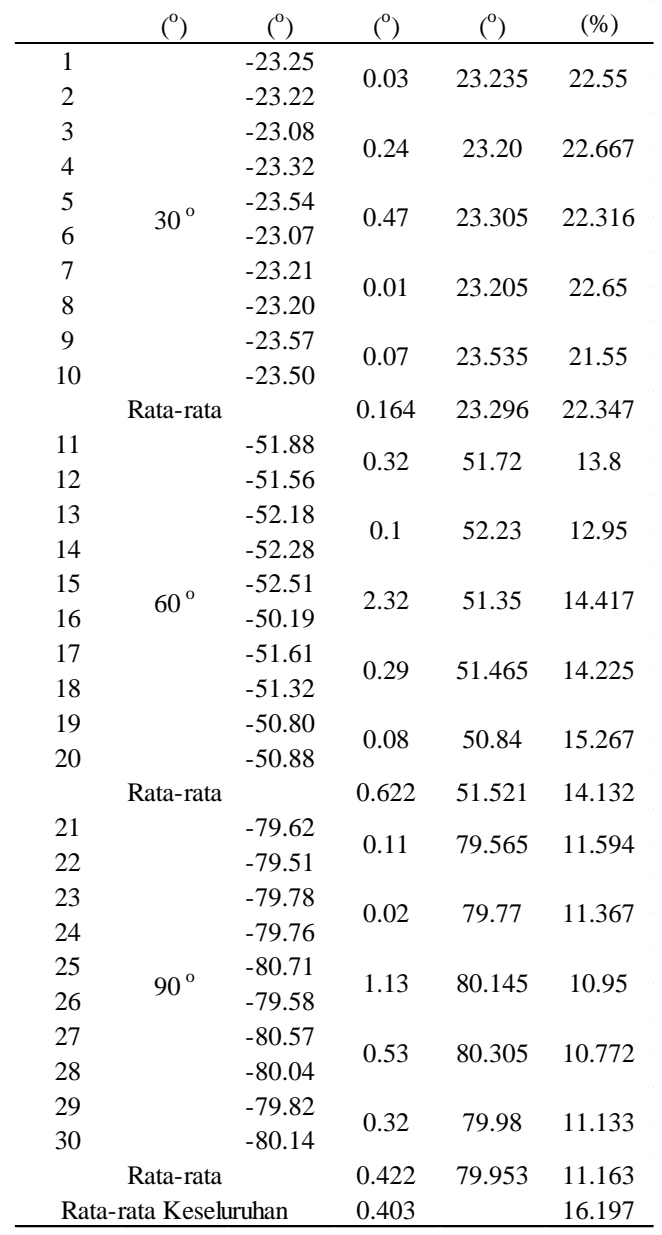




\section{Pengujian Sensor MPU6050 dengan Exponential Smoothing}

Tujuan dari pengujian ini adalah untuk mengetahui tingkat keakuratan sensor GY521 MPU6050 menggunakan metode exponential smoothing untuk melihat nilai sudut yang dikeluarkan sama dengan aslinya dan juga meghilangkan noise sehingga keluaran dari sensor MPU6050 memiliki error yang kecil. Hasil dari pengujian sensor MPU6050 menggunakan metode exponential smoothing saat sensor dimiringkan ke kanan terlihat pada tabel 3 dibawah ini.

\section{Tabel 3 Pengujian Sensor Miring Kanan}

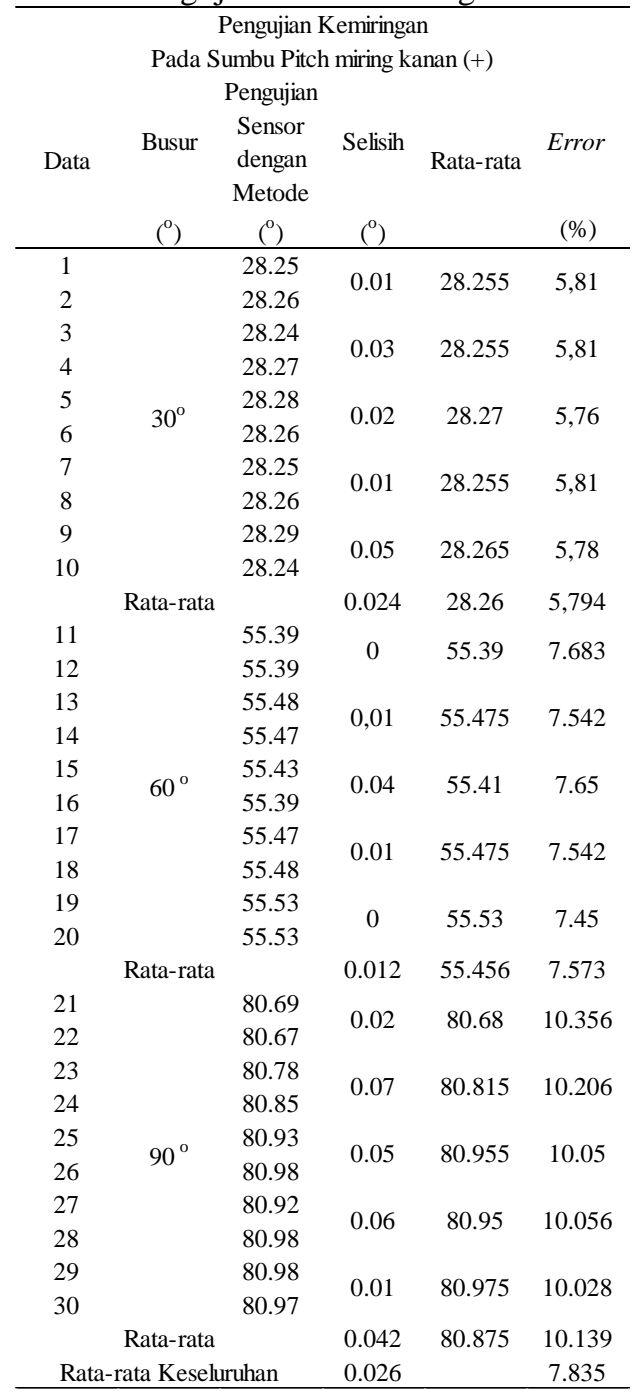

Tabel 3 diatas adalah hasil pengujian sensor ketika dimiringkan ke kanan dengan menggunakan busur untuk menentukan perbandingan dan error pada sensor MPU6050 tersebut. Untuk melakukan pengujian bisa dilihat pada tabel 4 dibawah ini

Tabel 4 Pengujian Sensor Miring Kiri

\begin{tabular}{|c|c|c|c|c|c|}
\hline \multicolumn{6}{|c|}{$\begin{array}{c}\text { Pengujian Kemiringan } \\
\text { Pada Sumbu Pitch miring kiri (-) }\end{array}$} \\
\hline Data & $\begin{array}{l}\text { Busur } \\
\left({ }^{\circ}\right) \\
\end{array}$ & $\begin{array}{c}\text { Pengujian Sensor } \\
\text { tanpa Metode } \\
\left({ }^{\circ}\right)\end{array}$ & $\begin{array}{l}\text { Selisih } \\
\left({ }^{\mathrm{o}}\right) \\
\end{array}$ & $\begin{array}{l}\text { Rata-rata } \\
\left(^{\circ}\right)\end{array}$ & $\begin{array}{r}\text { Error } \\
(\%) \\
\end{array}$ \\
\hline $\begin{array}{l}1 \\
2\end{array}$ & \multirow{5}{*}{$30^{\circ}$} & $\begin{array}{l}-25.67 \\
-25.66\end{array}$ & 0.01 & 25.665 & 14.45 \\
\hline $\begin{array}{l}3 \\
4\end{array}$ & & $\begin{array}{l}-25.67 \\
-25.65\end{array}$ & 0.02 & 25.66 & 14.467 \\
\hline $\begin{array}{l}5 \\
6\end{array}$ & & $\begin{array}{l}-25.69 \\
-25.70\end{array}$ & 0.01 & 25.695 & 14.35 \\
\hline $\begin{array}{l}7 \\
8\end{array}$ & & $\begin{array}{l}-25.73 \\
-25.66\end{array}$ & 0.07 & 25.695 & 14.35 \\
\hline $\begin{array}{c}9 \\
10\end{array}$ & & $\begin{array}{l}-25.62 \\
-25.60\end{array}$ & 0.02 & 25.61 & 14.633 \\
\hline \multicolumn{3}{|c|}{ Rata-rata } & 0.01 & 26.665 & 14.45 \\
\hline $\begin{array}{l}11 \\
12\end{array}$ & & $\begin{array}{l}-52.73 \\
-52.78\end{array}$ & 0.05 & 52.755 & 12.075 \\
\hline $\begin{array}{l}13 \\
14\end{array}$ & & $\begin{array}{l}-52.78 \\
-52.72\end{array}$ & 0.06 & 52.75 & 12.083 \\
\hline $\begin{array}{l}15 \\
16\end{array}$ & \multirow[t]{3}{*}{$60^{\circ}$} & $\begin{array}{l}-52.69 \\
-52.71\end{array}$ & 0.02 & 52.70 & 12,167 \\
\hline $\begin{array}{l}17 \\
18\end{array}$ & & $\begin{array}{l}-52.71 \\
-52.73\end{array}$ & 0.02 & 52.72 & 12.133 \\
\hline $\begin{array}{l}19 \\
20\end{array}$ & & $\begin{array}{l}-52.68 \\
-52.67\end{array}$ & 0.01 & 52.675 & 12.208 \\
\hline \multicolumn{3}{|c|}{ Rata-rata } & 0.032 & 52.72 & 12.133 \\
\hline $\begin{array}{l}21 \\
22\end{array}$ & & $\begin{array}{l}-80.93 \\
-81.02\end{array}$ & 0.09 & 80.975 & 10.028 \\
\hline $\begin{array}{l}23 \\
24\end{array}$ & & $\begin{array}{l}-80.94 \\
-80.97\end{array}$ & 0.03 & 80.955 & 10.05 \\
\hline $\begin{array}{l}25 \\
26\end{array}$ & $90^{\circ}$ & $\begin{array}{l}-80.97 \\
-80.94\end{array}$ & 0.03 & 80.955 & 10.05 \\
\hline $\begin{array}{l}27 \\
28\end{array}$ & & $\begin{array}{l}-81.02 \\
-81.02\end{array}$ & 0 & 81.02 & 9.978 \\
\hline $\begin{array}{l}29 \\
30\end{array}$ & & $\begin{array}{l}-81.08 \\
-80.98\end{array}$ & 0.1 & 81.03 & 9.967 \\
\hline & Rat & rata & 0.05 & 80.987 & 10.105 \\
\hline & Rata-rata & eseluruhan & 0.031 & & 12.229 \\
\hline
\end{tabular}

Hasil pengujian terhadap sensor MPU6050 terhadap sudut pitch (y) dengan melakukan pergerakan ke kanan dan ke kiri bisa disimpulkan bahwa nilai sudut pitch (y) yang keluar dari serial monitor tidak sama dengan nilai asli pada busur dimana pada saat miring kanan nilai rata-rata error pada sudut $30^{\circ}$ adalah $5.794 \%$ dengan rata-rata selisih sebesar $0.024^{\circ}$ pada sudut $60^{\circ}$ rata-rata error nya adalah $7.573 \%$ dengan rata-rata selisih sebesar $0.012^{\circ}$ dan pada sudut $90^{\circ}$ rata-rata error nya adalah $10.139 \%$ dengan ratarata selisih adalah $0.042^{\circ}$.

Sedangkan untuk miring kiri, error pada sudut $30^{\circ}$ adalah $14.45 \%$ dengan rata-rata selisih $0.01^{\circ}$, pada sudut $60^{\circ}$ adalah $12.133 \%$ dengan rata-rata selisih sebesar $0.032^{\circ}$ dan pada 
Tania Nur Alifah, dkk//Journal of Technology and Informatics (JoTI) Vol.1, No.2, April 2020, 108119

sudut $90^{\circ}$ rata-rata error nya adalah $10.105 \%$ dengan rata-rata selisih setiap perubahan sudut sebesar $0.05^{\circ}$. Hasil dari pengujian tersebut dapat disimpulkan bahwa nilai sudut y yang keluar pada sensor MPU6050 dengan menggunakan metode exponential smoothing tersebut terlihat lebih akurat dan perubahannya lebih stabil dibandingkan tanpa menggunakan metode

\section{Pengujian Sensitivitas Metode Exponential Smoothing}

Pengujian dilakukan untuk mengetahui berapa cepat perubahan sudut ketika sudut dimiringkan $90^{\circ}$. Pengujian dilakukan dengan menggunakan empat nilai $\alpha$ yang berbeda, yaitu $\alpha=0.2, \alpha=0.3$, $\alpha=0.6, \alpha=0.7$. Hasil pengujian bisa dilihat pada gambar 10 dan 11 dibawah ini

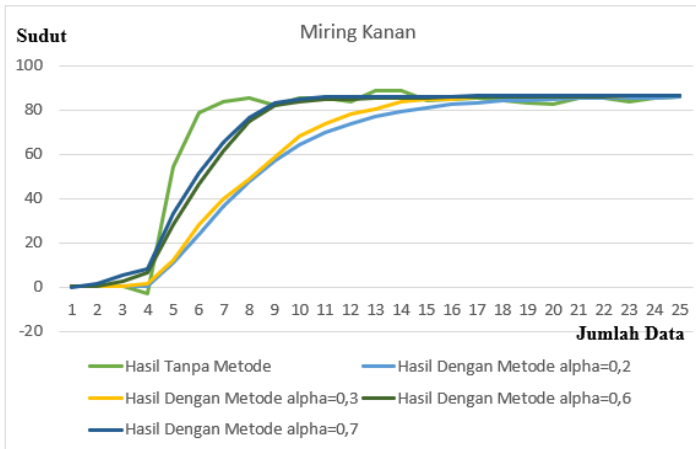

Gambar 10 Posisi Miring Kanan

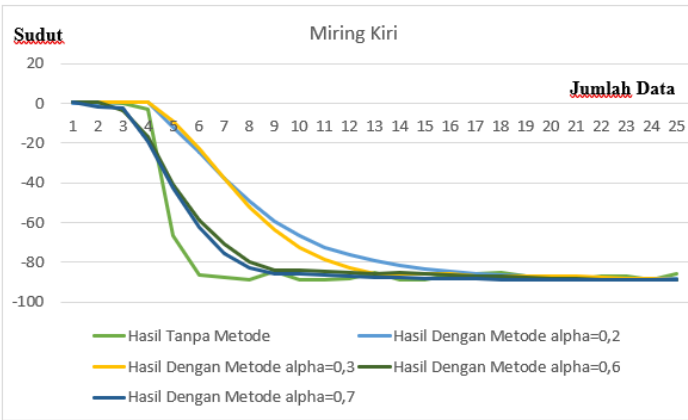

Gambar 11 Posisi Miring Kiri

Hasil pengujian dapat disimpulkan ketika sensor menggunakan metode exponential smoothing perubahan sudut lebih halus dari sudut yang paling kecil ke sudut yang paling rendah dan sudut stabil. Sedangkan untuk pengujian nilai $\alpha$, disimpulkan $\alpha=0.7$, perubahan sudut langsung menuju sudut yang diinginkan. Pengambilan data setiap 2 data per detik.

\section{Hasil Pengujian Sensor SW420}

Nilai yang diambil pada sensor getaran SW420 adalah nilai keluaran ADC. Pengujian pada sensor SW420 dengan melakukan menjatuhkan sensor tersebut dari ketinggian. Hasil pengujian bisa dilihat dari tabel 5 dibawah ini

Tabel 5 Pengujian SW420

\begin{tabular}{cccc}
\hline & \multicolumn{2}{c}{ Pengujian Getaran } & $\begin{array}{c}\text { Nilai } \\
\text { Getaran } \\
\text { (ADC) }\end{array}$ \\
\hline 1 & $1 \mathrm{~m}$ & 90 & 1024 \\
2 & $80 \mathrm{~cm}$ & 70 & 1024 \\
3 & $60 \mathrm{~cm}$ & 50 & 1018 \\
4 & $40 \mathrm{~cm}$ & 30 & 1018 \\
5 & $20 \mathrm{~cm}$ & 20 & 1009 \\
\hline
\end{tabular}

Hasil dari pengujian sensor getaran SW420 pada tabel di atas terlihat bahwa, ketika sensor getaran tersebut mengalami benturan atau goncangan yang dijatuhkan pada ketinggian dan sudut yang telah dilakukan, maka nilai ADC tertinggi yang dikeluarkan adalah 1024. Semakin rendah ketinggian sensor saat dijatuhkan, maka nilai ADC nya juga semakin berkurang. Ketika nilai sensor getaran pada posisi diam, maka nilai yang dikeluarkan oleh sensor getaran tersebut adalah 21 .

\section{Pengujian Modul GPS}

Tujuan dari pengujian ini adalah untuk memastikan bahwa modul Gps Neo 6m dapat mengakses lokasi dimana modul gps itu berada. Di bawah ini adalah hasil pengujian dari 10 lokasi yang berbeda untuk menguji modul GPS dapat mengakses lokasi tersebut. Pengujian dilakukan dengan membandingkan hasil keluaran lokasi dari sensor dan hasil keluaran lokasi yang diterima di google maps pada handphone, untuk menentukan perbedaan Latitude dan Longitude. Berikut hasil pengujian dan perbandingan dari Latitude lokasi dari keluaran sensor Modul GPS dan Lokasi pada Google Maps Handphone bisa dilihat pada tabel 6 dibawah ini. 
Tania Nur Alifah, dkk//Journal of Technology and Informatics (JoTI) Vol.1, No.2, April 2020, 108119

Tabel 6 Pengujian Latitude Lokasi

\begin{tabular}{ccccc}
\hline $\begin{array}{c}\text { No } \\
\text { Lokasi }\end{array}$ & Nama Lokasi & \multicolumn{2}{c}{ Latitude } & Error \\
He-1 & $\begin{array}{c}\text { Indomaret } \\
\text { Nginden, Depan } \\
\text { Untag }\end{array}$ & -730.009 .400 & -730.005 .933 & 0.00047492 \\
He-2 & $\begin{array}{c}\text { J1 Nginden Intan } \\
\text { Sel, Dekat Stikosa } \\
\text { Medokan }\end{array}$ & -730.773 .600 & -730.776 .817 & 0.00044021 \\
Ke-3 & $\begin{array}{c}\text { Semampir, dekat } \\
\text { rs gotong royong }\end{array}$ & -730.797 .100 & -730.801 .033 & 0.00053818 \\
Ke-4 & $\begin{array}{c}\text { Ruko Keputih } \\
\text { Akhishop }\end{array}$ & -729.229 .300 & -729.223 .083 & 0.00085254 \\
Ke-5 & $\begin{array}{c}\text { Perumahan } \\
\text { Keputih }\end{array}$ & -729.074 .300 & -729.085 .550 & 0.00154305 \\
Ke-6 & Jl Raya Kendal \\
Sari & -731.297 .200 & -731.297 .400 & 0.00002735 \\
Ke-7 & Jln Raya Darmo & -728.977 .600 & -728.963 .417 & 0.00194560 \\
& KFC Bungkul & & & \\
Ke-8 & Jln Darmo Kali & -729.610 .200 & -729.605 .500 & 0.00064418 \\
Ke-9 & Jln Margorejo & -731.813 .100 & -731.812 .000 & 0.00015031 \\
Ke-10 & Jln Sidosermo & -731.519 .700 & -731.514 .883 & 0.00065859
\end{tabular}

Rata-rata Error

0.00072749

Berikut pengujian Longitude lokasi bisa dilihat pada tabel 7 dibawah ini.

Tabel 7 Pengujian Longitude Lokasi

\begin{tabular}{|c|c|c|c|c|}
\hline \multirow[b]{2}{*}{ Lokasi } & \multirow[b]{2}{*}{ Nama Lokasi } & \multicolumn{2}{|c|}{ Longitude } & \multirow{2}{*}{$\begin{array}{c}\text { Error } \\
(\%) \\
\end{array}$} \\
\hline & & $\begin{array}{c}\text { Hasil } \\
\text { Handphone }\end{array}$ & Hasil Sensor & \\
\hline & Indomaret & & & \\
\hline $\mathrm{Ke}-1$ & $\begin{array}{l}\text { Nginden, Depan } \\
\text { Untag }\end{array}$ & 11.276 .863 .900 & 11.276 .868 .817 & 0.00004360 \\
\hline $\mathrm{Ke}-2$ & $\begin{array}{l}\text { J1 Nginden Intan } \\
\text { Sel, Dekat Stikosa }\end{array}$ & 11.276 .977 .300 & 11.276 .975 .433 & 0.00001656 \\
\hline $\mathrm{Ke}-3$ & $\begin{array}{c}\text { Medokan } \\
\text { Semampir, dekat } \\
\text { rs gotong royong }\end{array}$ & 11.278 .823 .500 & 11.278 .821 .967 & 0.00001359 \\
\hline $\mathrm{Ke}-4$ & $\begin{array}{c}\text { Ruko Keputih } \\
\text { Akhishop }\end{array}$ & 11.280 .969 .700 & 11.280 .967 .367 & 0.00002074 \\
\hline Ke-5 & $\begin{array}{l}\text { Perumahan } \\
\text { Keputih }\end{array}$ & 11.278 .647 .900 & 11.278 .651 .233 & 0.00002955 \\
\hline Ke-6 & $\begin{array}{c}\text { J1 Raya Kendal } \\
\text { Sari }\end{array}$ & 11.278 .524 .700 & 11.278 .524 .633 & 0.00000059 \\
\hline Ke-7 & $\begin{array}{c}\text { Jln Raya Darmo } \\
\text { KFC Bungkul }\end{array}$ & 11.273 .924 .500 & 11.273 .920 .067 & 0.00003932 \\
\hline $\mathrm{Ke}-8$ & Jln Darmo Kali & 11.274 .067 .000 & 11.274 .067 .767 & 0.00000680 \\
\hline $\mathrm{Ke}-9$ & Jln Margorejo & 11.274 .363 .900 & 11.274 .381 .550 & 0.00015655 \\
\hline $\mathrm{Ke}-10$ & Jln Sidosermo & 11.275 .163 .100 & 11.275 .164 .417 & 0.00001168 \\
\hline \multicolumn{4}{|c|}{ Rata-rata Error } & 0.00003389 \\
\hline
\end{tabular}

Dari hasil analisa pengujian Modul GPS neo 6m dan pengujian Lokasi pada Google Maps Handphone disimpulkan bahwa lokasi yang dikeluarkan Modul Gps Neo 6m mendekati hasil lokasi pada Google Maps Handphone. Setelah dilakukan pengujian antara lokasi dari sensor dan lokasi dari Handphone tersebut, maka hasil pengujian Latitude memiliki error sebesar 0.00072749 dan pengujian Longitude memiliki error sebesar 0.00003389. Modul GPS tersebut dapat mendeteksi lokasi dimana Modul Gps tersebut berada, akan tetapi setelah dilakukan uji coba didalam gedung, Modul Gps tidak bisa mendeteksi lokasi.

\section{Pengujian Aplikasi Telegram}

Pengujian dari pengiriman 10 teks dari esp8266 ke aplikasi telegram dan pengujian delay waktu yang dibutuhkan saat aplikasi telegram menerima pesan. Pengecekan delay yang diterima oleh aplikasi telegram menggunakan stopwatch untuk melihat perbandingan dari waktu yang diterima serial monitor dan waktu yang diterima oleh aplikasi telegram. Hasil pengujian dilihatpada tabel 8 dibawah ini

\section{Tabel 8 Pengujian Telegram}

\begin{tabular}{|c|c|c|c|c|}
\hline NO & Teks Yang Dikirim & $\begin{array}{c}\text { Waktu pada } \\
\text { Serial } \\
\text { Monitor }\end{array}$ & $\begin{array}{c}\text { Waktu Pada } \\
\text { Telegram } \\
\text { menerima } \\
\text { pesan }\end{array}$ & $\begin{array}{l}\text { Selisih } \\
\text { Waktu } \\
\text { (detik) }\end{array}$ \\
\hline 1. & Assalamualaikum & 09.22 .14 & 09.22 .18 & 4 \\
\hline 2. & Tugas akhir & 09.24 .48 & 09.24 .53 & 5 detik \\
\hline 3. & Tugas Akhir & 09.27 .27 & 09.27 .32 & 5 detik \\
\hline 4. & Tugas Akhir Titania & 10.51 .23 & 10.51 .27 & 4 detik \\
\hline 5. & $\begin{array}{c}\text { Deteksi } \\
\text { Kecelakaan }\end{array}$ & 11.05 .25 & 11.05 .29 & 4 detik \\
\hline 6. & Sepeda Motor & 18.15 .44 & 18.15 .48 & 4 detik \\
\hline 7. & Lihat Lokasi & 18.31 .42 & 18.31 .48 & 6 detik \\
\hline 8. & Coba Telegram & 18.40 .28 & 18.40 .32 & 4 detik \\
\hline 9. & Coba Telegram & 19.03 .07 & 19.03 .11 & 4 detik \\
\hline 10. & Selesai & 19.51 .22 & 19.51 .26 & 4 detik \\
\hline \multicolumn{4}{|c|}{ Rata-rata } & 4.4 detik \\
\hline
\end{tabular}

Tabel 8 diatas merupakan pengujian pengiriman dari esp8266 ke aplikasi telegram. Pengiriman teks ke aplikasi telegram telah berhasil dilakukan dengan delay waktu rata-rata yaitu 4.4 detik. Cek kembali koneksi internet ketika aplikasi telegram tidak menerima pesan 


\section{Pengujian Keseluruhan}

Pengujian Keseluruhan Penelitian ini bertujuan untuk melakukan pengujian terhadap keseluruhan sistem yang telah di buat dan dikerjakan sebelumnya. Dan memastikan bahwa seluruh perangkat dapat bekerja dengan baik setelah digabungkan semuanya. Pada tabel 9 dibawah ini yaitu pengujian jatuh pada 10 lokasi yang berbeda. Dimana peletakkan aplikasi telegram berada di JI Semolowaru tengah untuk melakukan pengujian jarak berpengaruh atau tidak pada pengiriman ke aplikasi telegram.

Tabel 9 Pengujian Keseluruhan

\begin{tabular}{|c|c|c|c|c|}
\hline Lokasi & Nama Lokasi & Jarak & Status & Keberhasilan \\
\hline $\mathrm{Ke}-1$ & $\begin{array}{l}\text { Indomaret } \\
\text { Nginden, } \\
\text { Depan Untag }\end{array}$ & $1.3 \mathrm{Km}$ & Jatuh & Berhasil \\
\hline $\mathrm{Ke}-2$ & $\begin{array}{c}\text { Jl Nginden } \\
\text { Intan Sel, } \\
\text { Dekat Stikosa }\end{array}$ & $2.1 \mathrm{Km}$ & Jatuh & Berhasil \\
\hline $\mathrm{Ke}-3$ & $\begin{array}{c}\text { Medokan } \\
\text { Semampir, } \\
\text { dekat rs } \\
\text { gotong royong }\end{array}$ & $2.2 \mathrm{Km}$ & Jatuh & Berhasil \\
\hline $\mathrm{Ke}-4$ & $\begin{array}{c}\text { Ruko Keputih } \\
\text { Akhishop }\end{array}$ & $6.2 \mathrm{Km}$ & Jatuh & Berhasil \\
\hline $\mathrm{Ke}-5$ & $\begin{array}{l}\text { Perumahan } \\
\text { Keputih }\end{array}$ & $2.9 \mathrm{Km}$ & Jatuh & Berhasil \\
\hline Ke- 6 & $\begin{array}{c}\text { Jl Raya Kendal } \\
\text { Sari }\end{array}$ & $2.4 \mathrm{Km}$ & Jatuh & Berhasil \\
\hline $\mathrm{Ke}-7$ & $\begin{array}{c}\text { Jln Raya } \\
\text { Darmo } \\
\text { KFC Bungkul }\end{array}$ & $5.4 \mathrm{Km}$ & Jatuh & Berhasil \\
\hline $\mathrm{Ke}-8$ & Jln Darmo Kali & $5.6 \mathrm{~km}$ & Jatuh & Berhasil \\
\hline $\mathrm{Ke}-9$ & Jln Margorejo & $5.3 \mathrm{~km}$ & Jatuh & Berhasil \\
\hline $\mathrm{Ke}-10$ & Jln Sidosermo & $4.5 \mathrm{~km}$ & Jatuh & Berhasil \\
\hline
\end{tabular}

Pada pengujian keseluruhan tersebut dilakukan uji coba jatuh dan alat diletakkan pada jok sepeda motor. Hasil uji coba tersebut dapat disimpulkan bahwa alat tersebut dapat mendeteksi lokasi ketika sepeda motor mengalami kecelakaan

\section{KESIMPULAN}

Berdasarkan hasil perancangan, implementasi dan pengujian hasil dari sistem yang telah dibuat dapat ditarik kesimpulan sebagai berikut:

1. Modul MPU6050 tanpa metode memiliki rata-rata kesalahan sebesar $9.214 \%$ pada miring kanan dan rata-rata selisih sebesar $0.464^{\circ}$, pada miring kiri error nya adalah $16.197 \%$ dan memiliki rata-rata selisih sebesar $0.403^{\circ}$. Jika sensor tersebut menggunakan metode exponential smoothing, rata-rata error berkurang menjadi $7.835 \%$ dan rata-rata selisih sebesar $0.026^{\circ}$ pada miring kanan, sedangakan pada miring kiri, rata-rata error sebesar $12.229 \%$ dan rata-rata selisih antar sudut sebesar $0.031^{\text {o. }}$

2. Pengiriman data atau informasi lokasi kecelakaan dilakukan dengan menggunakan aplikasi telegram dengan rata-rata delay pengiriman sebesar 4.5 detik .

3. Hasil uji coba lokasi pada sistem ini rata-rata error pada latitude sebesar $0.00072749 \%$ dan rata-rata error pada longitude sebesar $0.00003389 \%$

\section{SARAN}

Adapun saran untuk pengembangan penelitian selanjutnya adalah penggunaan modul GPS keluaran terbaru agar modul gps dapat mendeteksi lokasi di dalam Gedung.

\section{DAFTAR PUSTAKA}

[1] N. Fathurrahman, Rancang Bangun Smart Vehicle Untuk Mendeteksi Dini Kecelakaan dan Keadaan Darurat, Jurusan Teknik Elektronika, Politeknik Negeri Surabaya. EEPIS Final Project, 2011.

[2] A. Suprayogi, "Sistem Pendeteksi Kecelakaan Pada Sepeda Motor Berdasarkan Kemiringan Menggunakan Sensor Gyroscope Berbasis Arduino.," JPTII, pp. Vol. 3, No. 3, Maret 2019, 2019.

[3] A. M. Suhendra, Visualisasi dan Monitoring Lokasi Kebakaran Pada Security Room., Jurusan Elektronika, Politeknik Elektronika Negeri Surabaya, 2013.

[4] R. C. Prayogo, Perancangan Robot Berkaki 4 (Quadruped) dengan Stabilization Algorithm Uneven Floor Menggunakan 6- 
Tania Nur Alifah, dkk//Journal of Technology and Informatics (JoTI) Vol.1, No.2, April 2020, 108119

dof imu Berbasis Invers Kinematic, Departemen Teknik Elektro, Universitas Dipenegoro, 2018.

[5] E. M. Sari, Sistem Peramalan Stok Obat Menggunakan Metode Exponential Smoothing, Teknik Multimedia dan Jaringan, Fakultas Teknik, Universitas Trunojoyo., 2015.

[6] A. Nurhakim, "Pengaruh Sudut Roll Terhadap Perubahan Sudut Pitch Pada Sensor Accelerometer," Jurusan Teknik Elektro Fakutlas Sains dan Teknologi UIN SGD Bandung, 2018.

[7] Mu'azu, "New Approach for Determining the Smoothing Constan (alpha) of A Single Exponential Smoothing Method," International Journal of Research in Engineering., pp. 31-34, 2014.

[8] Z. Mukarromah, "Penetuan Konstanta Pemulusan Yang Meminimalkan Mape dan Mad Menggunakan Data Sekunder Bea dan Cukai KPPBC TMP C Cilacap," Prosiding Seminar Nasional Matematika dan Terapannya, pp. p-ISSN : 2550-0384; eISSN : 2550-0392, 2016.

[9] Rao, Demand Palnning and Forecasting, www.ciilogistics.com/knowledge/demand. ppt, diakses pada 8 November 2019, 2012. 